\title{
Músicas tradicionales en espacios académicos: la rueda de gaita como experiencia de aprendizaje ${ }^{1}$ \\ Traditional music in academic spaces: la rueda de gaita as a learning experience
}

Recibido: 17 de abril de 2015 - Revisado: 10 de septiembre de 2015 - Aceptado: 12 de abril de 2016

Nubia Paola Salazar Gutiérrez ${ }^{2}$

\begin{abstract}
Resumen
Las músicas tradicionales de Colombia han ganado espacio en los programas de educación musical. Actualmente, los educadores se preocupan por encontrar formas para aprovechar estas tradiciones en el ámbito académico. Este artículo se centra en la música de gaitas y tambores del Caribe colombiano. Por medio de una revisión de material bibliográfico, artículos investigativos, ponencias y trabajo de campo se estudian los elementos musicales y los procesos de enseñanza-aprendizaje presentes en esta tradición para hallar la manera de aprovecharlos en la academia. El análisis de los datos obtenidos y la aplicación de estos en una experiencia práctica sugieren que la rueda de gaita es una herramienta efectiva para integrar los conocimientos y la práctica musical.
\end{abstract}

Palabras clave

Educación musical, músicas tradicionales, gaitas y tambores, rueda de gaita.

\begin{abstract}
Traditional Colombian music has gained space in music education programs. Today, educators are concerned with finding ways to take advantage of these traditions in academia. This article focuses on the music of gaitas and drums of the Colombian Caribbean. Through a review of bibliographical material, research articles, papers and fieldwork, the musical elements and the teaching-learning processes present in this tradition are studied to find ways to take advantage of them in the academy. The analysis of the data obtained and the application of these in a practical experience suggest that la rueda de gaita is an effective tool for integrating musical knowledge and practice.
\end{abstract}

Keywords

Musical education, traditional music, gaitas and drums, rueda de gaita.

\footnotetext{
${ }^{1}$ Artículo de investigación derivado del proyecto "Enseñanza y aprendizaje en la música de gaitas y tambores" de la Universidad Sergio Arboleda, Bogotá, Colombia; y financiado por Colciencias.

${ }^{2}$ Egresada de la Universidad Sergio Arboleda, ganadora de la Beca-Pasantía otorgada por Colciencias para la realización del proyecto investigativo "Enseñanza y aprendizaje en la música de gaitas y tambores". M.sc. en Musicología en la Universidad Autónoma de Barcelona, España. Correo electrónico: paolasg8@gmail.com

Para citar este artículo use: Salazar, N. (2016). Músicas tradicionales en espacios académicos: la rueda de gaita como experiencia de aprendizaje. Civilizar Ciencias Sociales y Humanas, 16(31), 205-218.
} 


\section{Introducción}

Los modelos educativos de las instituciones de formación musical en Colombia han sido fuertemente influenciados por los modelos europeo y estadounidense. Esto ha privilegiado el aprendizaje de sus instrumentos, repertorios, historia y teoría, haciendo poco o ningún énfasis en las músicas tradicionales o populares (Castilla, 2010).

Las músicas tradicionales son aquellas que forman parte de la cultura e identidad de un grupo social y se transmiten de manera oral. La divulgación y enseñanza de estas músicas en los programas académicos se limitan a ser parte de una materia, por lo general llamada folclor, que debe estar dentro de un currículum académico estándar (Lambuley, comunicación personal, mayo 14, 2014). Al estar dentro de estos modelos basados en el eurocentrismo, se despoja a la música tradicional de su contexto cultural y se enseñan sus generalidades con el propósito de mostrar a los estudiantes otras músicas diferentes a las impartidas en la academia.

Este concepto reduce el aprendizaje evitando que se conozcan las relaciones sociales y el bagaje cultural que vienen atados a la tradición y que son importantes para la comprensión de dichas músicas.

Durante las últimas décadas, el interés por estudiar las músicas tradicionales propias se ha incrementado en varios países. En Colombia, publicaciones de la Pontificia Universidad Javeriana de maestros como Leonor Convers y Juan Ochoa (2007), Federico Ochoa Escobar (2013) y Alejandro Zuleta (2004), entre otros, son una evidencia. El auge de estas investigaciones hace que la academia empiece a cuestionarse sobre cómo enriquecer su labor a partir del estudio y la valoración de dichas músicas.

En artículos de maestros e investigadores latinoamericanos, puede observarse claramente el desarrollo de este tema. Por ejemplo, en "Sobre folclore y educación" (1977) de Dora de Zarate, escritora, maestra y folclorista panameña y en "La formación del músico popular en la República Dominicana" (1980) de Manuel Miniño. Ambos documentos de finales del siglo XX exponen la necesidad de incluir dentro de los programas educativos la música folclórica o tradicional, con el objeto de conservarla y de incluirla en escenarios nuevos en los que se difunda, se respete, se venere y se genere interés por ella (Zárate, 1977).

Miniño (1980) expone en su artículo una problemática entre los músicos académicos y los músicos populares de su país. Esta se centra en la apatía que muestra la academia musical por los músicos empíricos y por sus procesos de aprendizaje, planteando, que por ser escuela académica y desarrollar la enseñanza formal, están los unos por encima del nivel de los otros. El trabajo que se propone el autor, es romper con las barreras entre los dos grupos de músicos a fin de que cada uno le aporte al otro: a los músicos populares dándoles herramientas teóricas para que su música no se pierda en el olvido, y a los académicos abriéndoles la perspectiva y el camino para que incluyan la música tradicional y popular en sus repertorios, de manera que se conserve, enseñe, investigue y crezca, para el futuro (Miniño, 1980).

Esta es una discusión que aún ahora se vive con algunos educadores y directivos de las escuelas de música. Como las músicas tradicionales tienen procesos formativos diferentes, no manejan partitura y se enseñan dentro de un contexto no formal, se piensa que no son lo suficientemente válidas para ser enseñadas dentro de un espacio formal como lo son, en comparación, las grandes obras de los compositores europeos. El trabajo investigativo y las nuevas propuestas dentro de los espacios académicos empiezan a cambiar este pensamiento. Ejemplo de ello, es la labor que adelanta la Escuela Nueva Cultura ${ }^{1}$, la Facultad de Artes $\mathrm{ASAB}^{2}$ y otras universidades del país. 
Junto a este interés creciente por la recuperación de las músicas tradicionales está la inquietud de profesores e investigadores, con referencia al aprovechamiento de las músicas tradicionales para enriquecer la educación musical en la academia.

Recientes investigaciones en Estados Unidos e Inglaterra demuestran que dentro de las músicas tradicionales o populares de un país, en sus formas de enseñanza (las cuales se dan por lo general de manera oral), hay elementos enriquecedores para la educación musical actual y que es importante darles cabida en las escuelas (Green, 2002).

En Colombia esta discusión se da más en los ámbitos de la literatura, del lenguaje y de los relatos tradicionales orales que en la música. En el libro Pedagogía de la oralidad (2002) de Julio César Goyes, docente de la Universidad Nacional de Colombia, se propone la inclusión de los relatos tradicionales y expresiones orales -poesía, leyenda, relatos históricos- en los ejercicios de clase, con el objeto de aprovechar sus elementos narrativos y fortalecer las habilidades comunicativas y orales de los estudiantes.

La presente investigación pretende ser un aporte a la discusión en el ámbito musical. Se centra en la música tradicional de gaitas y tambores, originaria de los Montes de María en el departamento de Bolívar (Colombia). Para tal fin, se observa el contexto cultural, la tradición oral y las formas de enseñanza y aprendizaje de esta música, a la vez que se exploran los enfoques desde los que se pueden integrar dichos elementos a un programa educativo musical académico.

A partir de esta observación y del estudio de las formas de enseñanza y aprendizaje, se busca enriquecer los métodos de educación musical de la escuela académica para generar nuevos procesos de aprendizaje. También se espera aportar al incremento de la difusión de la música y la cultura caribe, de donde es originaria.

\section{Metodología}

La metodología que se utilizó es de carácter cualitativo, ya que se centra en un fenómeno humano como lo es la música. Se estudia cómo se relaciona esta con las personas y con la cultura; cómo se desarrolla su enseñanza y aprendizaje por medio de la oralidad, de una persona a la otra.

$\mathrm{Su}$ enfoque es etnográfico debido a que la música de gaitas y tambores forma parte de un territorio específico como son los Montes de María. Para comprender sus modos de enseñanza $\mathrm{y}$ aprendizaje es necesario estudiar su cultura.

Los procesos empleados para la recolección de información, siguiendo el enfoque cualitativo, son: la actualización de la bibliografía y el trabajo de campo en el que se observa el ambiente natural donde se despliega la música; así como también ambientes ajenos a ella. Se observan y experimentan las maneras en que los maestros enseñan la música. Se realizan entrevistas en Bogotá y en el municipio de San Jacinto (Bolívar, Colombia) a personajes expertos en la temática y a gestores de cultura. Dichas entrevistas permiten tener una visión del nivel de desarrollo de esta problemática en Bogotá.

Como etapa final se efectúa un taller con los alumnos de segundo semestre del programa de pregrado en música de la Universidad Sergio Arboleda (Bogotá, Colombia), mediante el cual se exploran las hipótesis que sugiere esta investigación y se analizan sus resultados.

\section{Desarrollo}

\section{La etnomusicología y la educación musical.}

Uno de los conceptos que se trabajaron durante el proceso de investigación es el de etnomusicología, que se define como el estudio de la música dentro de su contexto cultural (Nettl, 2005). Estudia las relaciones sociales 
generadas alrededor de la música y cómo la misma es un factor determinante en la cultura de un grupo social.

Dentro de los procesos investigativos de esta disciplina se encuentra el trabajo de campo. Es uno de los puntos más importantes y es la base de cualquier estudio etnomusicológico, ya que es la herramienta idónea para comprender realmente la música en el contexto cultural en el que nace y se desarrolla.

Al inicio de las prácticas de campo, el trabajo se centraba en recolectar y transcribir o grabar las melodías y ritmos, con el único propósito de conservarlos para la posteridad. Entre 1920 y 1960, se advirtió que no bastaba con recoger información, era esencial estar con la comunidad para generar sensibilidad hacia la cultura en estudio. A partir de los años ochenta el trabajo de campo se consolidó y es la fuente número uno de las investigaciones. La permanencia continua junto a las personas que viven esta música es fundamental para aprender y comprender el sistema musical característico.

Todo el análisis subsecuente y la interpretación de datos depende mucho del trabajo de campo, pero es a la vez la parte más personal del trabajo, la parte que realmente no puede ser enseñada, lo que cada uno de nosotros debe aprender por sí mismo, encontrando formas de mediar entre nuestra personalidad, con sus fortalezas y debilidades, y los individuos cuyas creencias compartidas aprenderemos e interpretaremos de manera confidencial y gran respeto (Nettl, 2005, p. 136).

Esta concepción de la etnomusicología ha cambiado, pues los investigadores buscan hoy por hoy que sus pesquisas no se queden en libros y publicaciones. Además, comienzan a preocuparse por aprender a interpretar la música como parte del trabajo de campo y se interesan por los mecanismos de enseñanza y aprendizaje como método para comprender mejor la música dentro de la cultura (Campell, 2013).
El nuevo rumbo que ha tomado la etnomusicología, inclinándose hacia la educación, buscando tener un diálogo permanente, ha logrado que en los últimos cincuenta años los límites entre la educación musical y la etnomusicología se desvanezcan paulatinamente.

Esta tendencia lleva a reconsiderar trabajos iniciales entre la musicología y la educación. En el siglo XIX, debido al nacionalismo, algunos músicos recopilaron expresiones musicales que representaban la cultura de pueblos lejanos de las ciudades de Hungría y Gran Bretaña. El ejemplo más significativo fue el trabajo que realizó Zoltán Kodály, al utilizar canciones del folclor húngaro para crear un método de enseñanza de la música para niños.

En los años sesenta algunos educadores en Estados Unidos se interesaron por las investigaciones etnomusicológicas, ya que consideraban importante que sus alumnos conocieran y aprendieran de otras músicas y culturas. Además, reconocieron la utilidad de colaborar con académicos de otras disciplinas para ampliar las percepciones de sus estudiantes sobre las músicas y sus creadores.

Los educadores se han dado cuenta de que a través de la música se pueden aprender muchas más cosas sobre las personas que no solo sonidos y cómo deben interpretarse. Aprenden sobre la vida de las personas, sobre su cultura. La etnomusicología se ha convertido en un recurso educativo en las escuelas de música ya que encierra otras formas y perspectivas de ver y estudiar la música (Netll, 2010, p. 2).

El repertorio escolar ha cambiado considerablemente gracias a estas investigaciones y a aquellos profesores que lograron introducir los sonidos y formas de otras culturas del mundo (Campell, 2013).

Por su parte, la etnomusicología al interesarse en los procesos de enseñanza y aprendizaje de músicos expertos y principiantes, se ha planteado interrogantes acerca de la pedagogía, 
del entrenamiento musical y de los sistemas educativos. Esto ha hecho que las instituciones académicas se cuestionen y procuren nuevas formas para enriquecer los antiguos procesos educativos.

El interés de la educación por la etnomusicología y viceversa, enriquece a ambos campos, produciendo una discusión sobre los desafíos para alcanzar una enseñanza efectiva de las diferentes culturas musicales, de los métodos que cada una de ellas exige, debido a sus características propias. La relación de estos dos campos puede generar muchos conocimientos que ayudarán a una mejor comprensión de la música, de la cultura y de la educación musical.

El panorama descrito, aunque es la perspectiva estadounidense, puede aportar al contexto colombiano. Los educadores, musicólogos y etnomusicólogos, están llevando sus proyectos investigativos al aula con el objetivo de aplicar sus resultados buscando estudiar las diferentes músicas tradicionales que existen en el país.

En ese sentido, esta investigación es una muestra de aquella naciente relación entre la educación y la investigación etnomusicológica. A través del trabajo de campo hace una observación de la cultura, así como de los procesos de aprendizaje-enseñanza de la música de gaitas y tambores, para luego llevarla al aula y realizar una prueba aplicada de estas formas de enseñanza.

\section{Enseñanza formal e informal.}

Se considera enseñanza formal de la música a aquella que se imparte dentro de unos parámetros específicos como lo son las teorías musicales, el solfeo y la armonía. Estos se ajustan a un programa de estudios que divide los conocimientos por niveles, por materias y por semestres (Green, 2002).

El aprendizaje informal es todo aquel que se genera por fuera de estos parámetros.
Suele ser el propio de las músicas tradicionales y populares y muchas veces forma parte de la cultura, por lo que se considera un proceso de enculturación.

La enculturación musical hace referencia a la adquisición de habilidades y conocimientos por la inmersión diaria en la música y en las prácticas musicales de un contexto social particular. Este proceso se da naturalmente en un medio social, ya que crecemos escuchando cierta música que nos influenciará siempre. Para algunos niños esta enculturación se convierte en un camino hacia la educación musical formal, en la que se aprende un instrumento y se desarrollan otras habilidades que no se experimentaron en su contexto social. Para otros niños, este camino musical se construye con una constante exploración de su entorno musical, la cual se da inconscientemente y forma a la mayoría de músicos populares (Green, 2002).

La enseñanza informal está presente en las músicas tradicionales de nuestro país, en las músicas que se transmiten por tradición oral. En Bogotá hay un ejemplo clave de la utilización de estos tipos de enseñanzas informales para la formación musical de niños: la Corporación Escuela de Formación Musical Nueva Cultura. Esta nace en el año 1988 a partir del trabajo realizado por la Fundación Nueva Cultura, un grupo de músicos investigadores enfocado en el estudio de las músicas tradicionales y urbanas, en su enseñanza y difusión.

La escuela en mención se distancia de los parámetros metodológicos que se emplean en otros centros de formación. Primero, porque es consciente de que el contexto cultural de estas músicas es cardinal para tener una concepción acertada de ellas y segundo, porque permite que la misma música, con sus características específicas, sea la que le guíe en la manera de abordarla y enseñarla (Sossa, 2014).

Este planteamiento sirve como referente $\mathrm{y}$ antecedente para las propuestas de la presente 
investigación. La música de gaitas y tambores forma parte de las músicas tradicionales de Colombia. Se transmite por tradición oral y no aplica ninguna metodología pedagógica utilizada en la academia.

Dos de los puntos más importantes de la Corporación Escuela de Formación Musical Nueva Cultura y que se comparten aquí son: a) la preocupación porque los maestros sean músicos que estén en permanente actividad musical, que toquen, escriban e investiguen estas músicas; y b) el hecho de que se empleen los elementos característicos como el ritmo, las canciones y los instrumentos de las músicas tradicionales para que, al mismo tiempo, los niños desarrollen habilidades diferentes a las musicales. Por ejemplo, ellos usan la percusión para desarrollar el manejo del cuerpo y de la espacialidad; y el canto para desarrollar el oído y el trabajo musical en grupo.

La música de gaitas y tambores, al igual que las actividades pedagógicas que aplica la Corporación Escuela de Formación Musical Nueva Cultura, maneja la práctica en grupo para enseñar valores como el respeto y la escucha al otro; a la vez, se ejercitan habilidades musicales como la memoria y el oído.

\section{El aprendizaje de los músicos populares según Lucy Green.}

La propuesta de incluir la enseñanza de la música de gaitas y tambores, siguiendo sus maneras tradicionales, en un contexto musical académico, se puede apoyar en las investigaciones hechas por Lucy Green, maestra investigadora de la Universidad de Londres, quien estudia los procesos de aprendizaje de los músicos populares en Inglaterra.

Para Green (2002) hay una gran brecha entre la música académica y la música popular, siendo la primera la fuente del conocimiento musical y la segunda la entretención del pueblo. Esta música popular, tan valiosa en el escenario cultural, es olvidada en la academia al no considerar sus procesos de enseñanza y aprendizaje como verdaderos. Cuando la autora habla de música popular se refiere al rock y al pop inglés.

Los músicos populares tienen procesos de aprendizaje diferentes a los de un músico de academia. Son distintos según el tiempo en que se desarrollan, mas no en sus contenidos. Un músico popular aprende de la práctica de la música que le interesa. Hace transcripciones, lo cual le ayuda a desarrollar el oído; imita o copia un tema en particular y así aprende el lenguaje propio de la canción, lo que mejora su interpretación; despliega procesos musicales dentro del contexto en que se mueve. Los procesos de aprendizaje de los músicos populares son tan reales como los vividos en la academia y pueden enriquecer, con algunos de sus elementos, las formas empleadas en las escuelas. Estos procesos se mueven entre dos vertientes: la enculturación y el aprendizaje consciente y autodidáctico.

Como ya se mencionó, la enculturación es el aprendizaje de habilidades musicales por la inmersión diaria en una música y en una cultura específicas. El proceso comienza cuando el músico popular, casi siempre a una corta edad, toma la música que le gusta $-\mathrm{y}$ le interesa- $\mathrm{y}$ empieza a aprenderla conscientemente, escuchándola con atención, copiando y transcribiendo algún tema musical en especial. También de manera inconsciente, cuando el acto de escuchar se hace por placer o distracción, o simplemente como compañía de alguna otra actividad diaria.

La música popular tiene dos momentos cruciales en su aprendizaje: uno es en solitario, donde ocurre la experimentación de instrumentos, la transcripción de temas de interés propio, la improvisación del mismo tema y la composición. El otro sucede en grupo, donde se da la práctica musical y se aprende al compartir con los demás, oyéndolos, imitándolos, hablando, recibiendo indicaciones $\mathrm{y}$, de manera incons- 
ciente, observando. A través de estas prácticas se adquieren habilidades como el desarrollo auditivo, la improvisación, la composición, la técnica en el instrumento y a veces, la teoría musical (Green, 2002).

Los conceptos que se apropian no son distintos de los aprendidos formalmente en la academia. Lo importante y diferente de estos procesos es que los conceptos se aprenden todos juntos dentro de un mismo contexto, relacionándolos entre sí y poniéndolos en práctica. En la academia, estos conceptos se aprenden por separado, por fuera del escenario en que se desarrollan y muy pocas veces se relacionan entre sí. Aunque el aprendizaje en ambos casos se da de maneras diferentes, el desarrollo musical es similar:

No es suficiente el aprender inconscientemente o de manera natural, todos los músicos populares buscan la perfección de sus habilidades. Algunos de ellos se apoyan con estudio y clases formales, pero siempre está presente la práctica y el estudio personal (Green, 2002).

El aprendizaje de la música por enculturación brinda al músico una mayor expresión al momento de interpretar, puesto que este conoce el lenguaje y su aprendizaje se ha dado naturalmente. Mientras tanto, en la educación formal se tiende a enseñar con músicas ajenas y poco o nada conocidas por el músico.

La música de gaitas y tambores es entonces un perfecto ejemplo del proceso de enculturación. Los músicos crecen inmersos en este contexto musical convirtiéndose así en grandes maestros de esta música, en fabricantes de instrumentos y en compositores.

\section{La música de gaitas y tambores.}

En el departamento de Bolívar se origina esta música con rasgos indígenas y negros reflejados en sus melodías, ritmos einstrumentos. La gaita es un instrumento autóctono fabricado con cardón de cactus, cera de abeja montuna y pluma de pato macho, materiales totalmente naturales. Se construyen en pareja, hembra y macho. La primera interpreta las melodías; el segundo, las acompaña. Por la naturaleza de sus materiales deben elaborarse al mismo tiempo y con iguales dimensiones para que su afinación coincida. Los tambores se fabrican con conos huecos de madera y piel de venado hembra o en su defecto, de chivo (Ochoa-Escobar, 2013). Los nombres de los tambores son: Alegre, Llamador y Tambora. El músico que toca la gaita macho también lleva el maracón, una maraca hecha con un totumo y semillas naturales y con la que se completa el grupo musical.

La música de gaitas y tambores se transmite a través de la tradición oral, del maestro al alumno directamente. La forma de enseñanza de esta música se basa en los actos de escuchar, observar e imitar. Por medio de la oralidad el maestro le enseña a su alumno las melodías y ritmos, y le comparte su experiencia como músico. En el pueblo cuando un niño o joven está interesado en aprender a tocar algún instrumento busca a un maestro y le pide que le enseñe. Por lo general, estos maestros están dentro de su propia familia y pueden ser un tío o un abuelo o su padre.

Dicha música, también está ligada profundamente a la cultura y a la identidad de estos pueblos. Los patios de las casas son y han sido por tradición el lugar más importante, no solo por ser el más fresco sino porque en él se cocina, se come, se baila, se lava y se construyen los instrumentos. Además, yacen allí los animales y los cactus, se comparte socialmente, se enseña y se aprende a tocar los instrumentos, se festeja y se teje. En el patio transcurren todas las actividades sociales y familiares de la comunidad.

En los patios suceden tres actividades significativas dentro de la cultura del lugar: el tejido, la fabricación de los instrumentos y las fiestas o ruedas de gaita. En el patio es normal 
ver los cardones de cactus, o los conos de madera secándose al sol junto con los cueros de vaca que serán en el futuro llamadores, alegres y tamboras; los niños y jóvenes aprenden de sus mayores a fabricar estos instrumentos, convirtiéndose ello en oficio de familia.

Las ruedas de gaita son reuniones de gaiteros y tamboreros que se encuentran para tocar y celebrar algún acontecimiento importante. Los grupos de músicos son llamados para todo tipo de celebración. De estas fiestas los niños de la comunidad aprenden y se van interesando en esta música, viendo y escuchando a los músicos tocar en vivo. Así experimentan la música y la cultura desde pequeños.

Como los niños y jóvenes experimentan la música de varias formas, su aprendizaje se da también de un modo natural. El joven se reúne con su maestro, y este por medio de indicaciones y muestras de cómo se toca el instrumento, le va enseñando poco a poco. Cuando el alumno va adelantado en su habilidad con el instrumento, el maestro lo lleva con él a las parrandas o toques para que vaya desarrollando confianza con el instrumento.

Francis Lara, gaitero y tamborero de San Jacinto y uno de los representantes de esta tradición, aprendió de su abuelo a tocar la gaita y el tambor alegre. Su abuelo era José Lara, uno de los músicos más distinguidos de la región. En una entrevista describe cómo aprendió de su abuelo:

[...] cuando yo veía esas parrandas que hacían allá en la casa, mi abuelo, mis tíos [...] pues yo siempre quedaba embelesado como dice uno, mirando, mirándolos tocar [...] el abuelo mío practicaba mucho alegre, tocaba su vaina, su tambor y yo me quedaba mirándolo y yo sí quería tocar como él, decía yo, y yo dije:-papi yo quiero tocar como usted toca. -iAjá mijo y entonces! Y la gaita, ¿la vas a dejar? -No, yo la cojo ahí de vez en cuando pero explíqueme estas cosas por acá. Y desde ahí comencé yo a tocar alegre, a aprender con él, desde muy niño [...] (Lara, F. comunicación personal, 6 de mayo, 2013).

En otra entrevista, Francis habla de cómo aprendió a tocar gaita y lo compara con la forma en que él enseña en Bogotá:

[...] mi abuelo no me decía a mí, destapa este primero, destapa este otro, ¡no señor! era la canción como era [...] yo tenía que cogérsela ahí ahí, la vas buscando, entonces uno utiliza mucho el oído y crece uno con eso [...] lo mismo lo que era percusión, igual, se ponía ahí en frente y comenzaba a tocar y uno mirando, a cogerse las cosas. Ahora uno dice: primero esta mano dos veces luego esta otra, vamos a sacar este sonido y así [...] (26 de marzo, 2014).

Explica que la razón del cambio de las indicaciones que él les da a sus alumnos con respecto a las que su abuelo le daba a él, se debe a que los muchachos de la ciudad no crecen con esta música y que para ellos es algo nuevo. Mientras que para los músicos que crecen escuchando esta música y viviéndola es más fácil. Forma parte del proceso de enculturación.

La música, al ser un aspecto sustancial de la vida diaria, toma los elementos que la componen, tales como el baile, las letras de las canciones y las melodías del entorno social. A la vez aporta estos y otros elementos a la cultura e identidad del pueblo. Es por esto que al conocer y aprender la cultura en la que está inmersa esta música, su interpretación se acerca mucho más a la realidad y la experiencia se vuelve más cercana.

La música de gaitas y tambores contiene elementos culturales valiosos que deben reconocer y respetar los jóvenes y niños que están en formación. Su interpretación trae como consecuencia, el afianzamiento de habilidades musicales específicas como lo son: desarrollar el oído, tocar con otros, entender el papel que desempeñan los instrumentos dentro de una música en particular, saber escuchar e interesarse por el contexto cultural de la música, entre otras más 
que dependen también de los procesos personales de los alumnos. Por lo tanto, son aportes a la educación académica que enriquecen la formación musical y son conocimientos que en la escuela no se aprovechan.

La enseñanza y difusión de esta música, teniendo en cuenta su contexto cultural, sus características musicales y sus modos de enseñanza, abren la visión de los estudiantes de música hacia otros horizontes. La experiencia con este tipo de músicas aporta en su desarrollo profesional.

\section{La rueda de gaita.}

La rueda de gaita es una expresión social y festiva en la que gaiteros y tamboreros se reúnen a tocar y, alrededor de ellos, se juntan personas que bailan, cantan y celebran. Esta práctica es ancestral y es heredada de la tribu africana bantú, la cual predominó en la época de la colonización en Colombia. La práctica africana consistía en un círculo cerrado: en la mitad se ubicaba un grupo de tamborileros tocando, y a su alrededor unos bailarines danzando al ritmo de los tambores. El baile era excitante y se iba incrementando su ritmo hasta que la música llegaba a su punto más alto. Entonces los bailarines se detenían de repente y caían al suelo. Este, se considera el origen del baile de la cumbia.

La rueda de gaita comparte algunos elementos con la práctica musical africana: el círculo alrededor de los músicos y las personas bailando. En los pueblos la rueda es sinónimo de fiesta; hasta hace algunos años se usaba en todas las celebraciones. Sin embargo, la gran influencia de los medios de comunicación como la radio y la televisión, han hecho que la práctica de la rueda de gaita se pierda debido a que la música tradicional no está dentro de su programación habitual. El consumo diario de música popular, tropical y urbana, resta importancia a dichas músicas, llevándolas casi al olvido. En consecuencia, esta práctica festiva, se puede apreciar solo cuando hay festival.
La rueda de gaita tiene su paralelo con otras músicas tradicionales que han alcanzado estándares académicos, como el jazz y el choro. El jazz antes de ser reconocido en las escuelas de música estadounidenses, era la música tradicional de los asentamientos negros en este país, sobre todo en Nueva Orleans durante el siglo XIX (Gioia, 2011). Había una práctica festiva que consistía en reunirse en Congo Square, hoy conocido como Louis Armstrong Park. En el centro de la reunión permanecía el grupo de tambores e instrumentos de cuerda fabricados con calabazas. Alrededor de ellos se ubicaban muchas personas (en su mayoría afroamericanas), formando círculos y bailando al compás de la música. Algunas mujeres se ubicaban cerca de los músicos, cantando. Los movimientos de los bailarines, algunos suaves, otros enérgicos, se asemejaban a los del baile de la cumbia.

Hoy en día esta manifestación festiva ya no se da, pero un recuerdo de ella son las reuniones de músicos de jazz para tocar de manera improvisada, las cuales llevan por nombre jam session.

Por otra parte, el choro es una música tradicional brasilera que también tiene lugar en la academia musical pero que continúa asumiéndose como una práctica social parecida a las mencionadas. Esta se llama Roda de choro y es la reunión de músicos que se juntan para tocar y compartir con otros. El choro al igual que la música de gaitas es de tradición oral y tiene particularidades que comparte con esta. No utiliza partituras, ya que no es posible escribir todo lo que un músico interpreta en una roda. La partitura es un buen instrumento para registrar los temas y para estudiarlos, mas no para hacer una interpretación fiel.

Un choro no suena igual al ser ejecutado por diferentes músicos, cada uno lo interpreta a su manera. La partitura solo detendría a una persona que la lee y no conoce el lenguaje musical del choro, pues, este debe interpretarse de memoria. La cultura del choro se comprende 
y se aprende compartiendo e interactuando con otros músicos de choro. Para este fin la roda es un ambiente de aprendizaje y conocimiento del repertorio y del lenguaje de la música. La interacción con otros músicos enriquece el repertorio personal. Al tener más repertorio, al interactuar con otros músicos y al participar en muchas rodas, se obtiene mayor lenguaje musical (Fiorussi, 2012). Así pues, esta roda se convierte en una experiencia de aprendizaje $\mathrm{y}$, participando en ella, es como se aprende el lenguaje de esta música.

Al igual que estas dos expresiones sociales que pasaron a ser experiencias de aprendizaje, la rueda de gaita puede convertirse también en eso: una experiencia en la que se aprende de la música, del lenguaje y de la cultura de las gaitas y los tambores.

En la rueda de gaita confluyen algunos elementos que en la escuela académica se excluyen de la formación musical: los aspectos festivo y social, el uso del cuerpo y el baile. Dichos elementos permiten que el aprendizaje sea una experiencia y no solo un conocimiento que se recibe y se memoriza. Los conocimientos necesitan ponerse en práctica para ser interiorizados y asimilados completamente.

La propuesta de este trabajo es plantear que la música de gaitas y tambores se enseñe siguiendo sus formas propias de instrucción, por tradición oral. Así mismo, que la rueda de gaita se convierta en una experiencia de aprendizaje en la que el alumno pueda tocar con los demás miembros del grupo, aprender los temas y las letras de las canciones, moverse y bailar al ritmo de la música y tenga una experiencia de esta, diferente a las formas implementadas en la academia.

\section{El taller de gaitas y tambores.}

Para efectos de esta investigación se realiza un taller en el que se explora la rueda de gaita como estrategia de enseñanza. La experiencia se realiza con el grupo de segundo semestre del programa profesional de música de la Universidad Sergio Arboleda, en el marco de la asignatura de folclor. La edad promedio del grupo está entre los 17 y los 20 años.

El taller se divide en dos sesiones: en la primera se describe el contexto cultural de la música de gaitas y tambores, se habla de la historia, del territorio, de las herencias interculturales, de los instrumentos y de los músicos. Para esta sesión se invita al grupo San Jacinto 4G, el cual da una demostración de la música y habla directamente con los estudiantes respondiendo preguntas sobre sus conocimientos y experiencias personales.

Durante la segunda sesión se efectúa la práctica musical por medio de la enseñanza tradicional y se lleva a cabo la experiencia de la rueda de gaita. Se crea un ambiente festivo mediante una sesión, en la que se les pide que imaginen estar en el patio de una casa de San Jacinto, donde se ha convocado una rueda de gaita y ellos son los músicos de la fiesta. El invitado del taller fue Francis Lara, gaitero y tamborero sanjacintero, quien enseñó a los estudiantes a tocar los instrumentos y les explicó en qué consistía una rueda de gaita. A través de sus experiencias les enseñó la manera como se debe interpretar esta música.

La enseñanza de los instrumentos se hace por medio de la oralidad: el maestro muestra los ritmos en los tambores y la melodía en la gaita, mientras los estudiantes lo imitan. Se escoge un tema específico para realizar el montaje. Después, en la rueda de gaita, el tema lleva letra para facilitar la participación de todos los asistentes. A diferencia de las clases tradicionales de la academia en las que las sillas de los salones se organizan en filas, en el taller forman un círculo. Ello permite que todos los estudiantes participen de manera activa y ejerzan una función.

La rueda de gaita es el momento que reúne a todos los estudiantes en torno a los 
instrumentos, para comenzar a tocar el tema escogido. Los que no están tocando en ese momento participan cantando y poco a poco se animan a bailar. El tema se interpreta varias veces, mientras los alumnos se rotan los instrumentos; participando así de diferentes formas. Esto hace experimentar la música desde distintas perspectivas: tocando algún tambor o gaita, cantando, bailando o simplemente escuchando.

En la academia, la música tiende a enseñarse a través de contenidos fijos. El aprendizaje está mediado por un profesor que expone los conceptos y es trabajo del estudiante interiorizarlos. Por el contrario, con el taller de gaitas se busca que el aprendizaje fluya a través de la práctica, que sea una vivencia. Que el salón de clase se transforme en un espacio para vivir la música, para explorar y experimentar, y que no solo sea el escenario donde se aprenden teorías y conceptos musicales.

Mientras que en la academia se estudia en grupos de personas del mismo nivel de conocimientos, en la música de gaitas el aprendiz se relaciona todo el tiempo con su maestro y con otros músicos que saben más que él. Asiste a las fiestas y a los conciertos con su maestro y puede empezar a participar en ellos, inicialmente con lo más sencillo. En la academia, el contacto con personas o maestros profesionales se da a través de un concierto, mediante la relación artista-público. En el taller los alumnos pueden experimentar y a la vez compartir con músicos que dominan esta práctica, que construyen instrumentos y que proporcionan información de primera mano sobre la cultura y la tradición de la misma.

Esto produce un cambio en los alumnos, ya que no se conforman con lo que el profesor les enseña, buscan formas para resolver sus inquietudes y necesidades personales. Algunos estudiantes que asistieron al taller han intentado ponerse en contacto con los gaiteros y tamboreros para aprender de ellos.
En el transcurso del taller, se pidió a los estudiantes que imaginaran estar en el pueblo de San Jacinto y que recordaran su contexto cultural expuesto en la primera sesión, esto permitió una verdadera inmersión. El resultado fue conseguir que la rueda de gaita se viviera de una forma casi espontánea, la música llevó al grupo a la rueda y a la fiesta.

El ambiente festivo que caracteriza a la rueda de gaita se alcanzó prontamente. Los estudiantes se relajaron y experimentaron la música bailando y cantando (habilidades innatas que son un primer contacto con la música). Este es otro punto que enriquece el aprendizaje dentro de la academia.

En una clase corriente en la escuela, el ambiente es muy serio, formal y controlado. Las clases son estáticas y el único movimiento corporal es el que se realiza al aprender a tocar un instrumento. El taller de gaitas cambia totalmente el ambiente formal, pues la música y la rueda son festivas. La música llama al baile por sus ritmos alegres, lo que hace que el estudiante pueda relacionarse con la misma, no solo tocando un instrumento sino también bailando y cantando.

El baile y el canto son expresiones musicales que cada persona posee. Son dispositivos directos para experimentar la música. En la academia no hay espacio para explorar estas actividades. Aunque los cantantes desarrollan el canto, lo hacen como se estudia un instrumento: con técnicas y métodos, pero no como un modo de experimentar la música.

En el taller, al formarse la rueda, el baile y el canto afloraron naturalmente. Los estudiantes que no tomaron instrumentos inicialmente, pudieron tener esta conexión directa con la actividad. Así aprendieron la melodía y el ritmo, comprendieron la forma musical del tema y se integraron a la fiesta. De tal manera que dicha actividad se transformó en una experiencia de aprendizaje. 
La música de gaitas y tambores puede enseñarse dentro de los parámetros académicos, siendo explicada teóricamente y mediante partituras ya existentes. Sin embargo, la propuesta de este trabajo consiste en acercar a los alumnos a la música tradicional por medio de la exploración y la práctica directa. La forma de enseñanza a través de la oralidad, además de enseñar a interpretar el instrumento, enseña el lenguaje musical propio. Con la práctica de la rueda de gaita, este lenguaje se consolida mucho más al tocar con el ensamble.

El contacto con los instrumentos y la rueda de gaita ayuda a las personas a experimentar una música que en muchos casos no conocen y a formar parte de un ensamble de gaitas y tambores; además las aproxima a la práctica real de la música.

\section{Conclusiones}

El estudio de las formas de enseñanza y aprendizaje presentes en la música de gaitas y tambores, junto con sus elementos, facilita reconocer que sí es posible aportar y enriquecer la enseñanza musical dentro de la academia.

Es posible abrir un espacio a la enseñanza por tradición oral sin el temor de no alcanzar conocimientos musicales reales. Aunque la música de gaitas y tambores no maneja partitura, con su enseñanza oral se transmiten todos los conocimientos contenidos en ella. Al realizar el taller de gaitas se les permitió a los estudiantes experimentar la música y vivirla generando el aprendizaje mediante la práctica.

En el taller se experimentó la rueda de gaita, la cual abre el espacio para la práctica, la interpretación y la exploración. El taller ayuda a conocer la cultura y la música a partir de una fuente primaria, al invitar músicos tradicionales propios de ellas.

El acercamiento a la música de formas naturales como el baile y el canto, facilita inte- riorizarla. Se puede aprovechar una expresión social y festiva - la rueda de gaita- como una experiencia de aprendizaje en la que se logre el intercambio de saberes musicales.

$\mathrm{Al}$ abrir el espacio a la música de gaitas y tambores, y permitir que se enseñe de la forma tradicional, se está invitando al estudiante a conocerla de una manera cercana a la realidad y no convertirla en algo artificial, separada de su contexto cultural, social y festivo.

Al incluir las músicas tradicionales en los programas académicos, abriéndoles un lugar para que se desarrollen y se enseñen con todas sus características, se le está brindando a los estudiantes un conocimiento más amplio de los distintos tipos de música y las diferentes clases de enseñanza de la misma, lo que amplía su visión musical.

\section{Notas}

${ }^{1}$ Escuela que nace del trabajo investigativo y de proyección artística de la Fundación Nueva Cultura, la base de sus programas son las músicas regionales y urbanas de Colombia y las manifestaciones sonoras del Caribe iberoamericano.

${ }^{2}$ Es la Facultad de Artes de la Universidad Distrital Francisco José de Caldas (Bogotá, Colombia). En el área de música, sus procesos formativos se apoyan en gran parte en

\section{Referencias}

Campell, P. S. (2013). Etnomusicología y educación musical: punto de encuentro entre música, educación y cultura. Revista internacional de educación musical, 1, 42-52. doi: 10.12967/ RIEM-2013-1p042 -052

Castilla, R. M. (2010). El papel de la etnomusicología en la educación y en la gestión de las políticas culturales. Revista 
HAOL, 23, 85-97. Recuperado de http:// www.historia-actual.org/Publicaciones/ index.php/haol/article/view/500/407

Convers, L., \& Ochoa, J. S. (2007). Gaiteros y tamboleros: material para abordar el estudio de la música de gaitas de San Jacinto, Bolivar. Bogotá D.C.: Pontificia Universidad Javeriana.

De Zárate, D. P. (1977). Sobre folclore y educación. Revista Música casa de las Américas, 62, 33-36.

Fiorussi, E. (2012). Roda de choro: processos educativos na convivência entre músicos (Tesis de Maestría). Universidade Federal de São Carlos. Recuperado de http:// www.processoseducativos.ufscar.br/diss eduardo_2012

Gioia, T. (2011). The history of jazz. Nueva York: Oxford University Press, Inc.

Goyes-Narváez, J. C. (2002). Pedagogía de la oralidad. Bogotá D.C. Ofis vmp limitada.

Green L. (2002). How popular musicians learn. A way ahead for music education. Londres: Ashgate Publishing Limited.

Miniño, M. A. (1980). La formación del músico popular en la República Dominicana. Revista Música Casa de las Américas, 81, 19-32.
Nettl, B. (2005). The study of ethnomusicology: thirty-one issues and concepts (2da ed.). Estados Unidos: Board of Trustees of the University of Illinois.

Nettl, B. (2010). Music education and ethnomusicology: a (usually) harmonious relationship. MinAd: Israel Studies in Musicology Online, 8(1). Recuperado de http://www.biu.ac.il/hu/mu/min-ad /10/01-Bruno-Nettl.pdf

Ochoa-Escobar, F. (2013). El libro de las gaitas largas: tradición de los Montes de María. Bogotá D.C.: Pontificia Universidad Javeriana.

Sossa, J. (septiembre, 2014). Procesos de iniciación musical en edades infantiles y juveniles a través de las músicas tradicionales: una mirada desde la experiencia de la Corporación Escuela de Formación Musical Nueva Cultura. Conversatorio presentado por FLADEM. Pontificia Universidad Javeriana, Bogotá, Colombia.

Zuleta, A. (2004). El método kodály y su adaptación en Colombia. Cuadernos de Música, Artes Visuales y Artes Escénicas, 1(1), 66-95. Recuperado de http:// revistas.javeriana.edu.co/index.php/cma/ article/viewFile/6420/5100 
